\title{
Time, Physics and Neuroscience
}

\author{
Paolo Di Sia ${ }^{1-3}$ \\ ${ }^{1}$ University of Padova, School of Science \& School of Medicine, Padova (Italy) \\ Dept. of Physics and Astronomy \& Dept. of Neurosciences \\ ${ }^{2}$ paolo.disia@unipd.it \\ ${ }^{3}$ www.paolodisia.com
}

\begin{abstract}
It has been suggested by some authors that time has no physical existence, but it would be an illusion. The human being uses clocks for measuring the numerical sequential order of the duration of material changes, namely the motion which runs in space. We experience a run of changes in the frame of the linear psychological time "past-present-future", which has its basis in the neurological activity of the brain. We could link it with a concept of universe where there is neither physical past nor physical future. In this model of "time-free" space (in the physical sense) it exists only what we observe with our senses and measure with apparatuses.
\end{abstract}

Keywords: Time; Physics; Philosophy of Science; Cognitive Psychology; Neuroscience.

\section{References}

[1] Barbour, J.

[2] Jaffe, A.

[3] Kilmister, C.W.

[4] Małkiewicz, P.

[5] Gomes, H.

[6] Di Sia, P. On philosophy of mind, quantum physics and metaphysics of the uni-multiverse. PHILOSOPHICAL NEWS, 18, 161-174 (2020). 
[7] Di Sia, P. On Quantum Physics, Metaphysics and Theism. In: Relations. Ontology and Philosophy of Religion, Milan-London: Mimesis International (2018).

[8] Anderson, E., Barbour, J., Foster, B.Z., Kelleher, B., Murchadha, N.O.

[9] Girelli, F., Liberati, S., Sindoni, L.

[10] Rovelli, C.

[11] Rovelli, C.

[12] Prati, E.

[13] da Costa, N.C.A., Bueno, O., French, S.

[14] Buhusi, C., Meck, W.

[15] Mauk, M.D., Buonomano, D.V.

[16] Ivry, R.B., Spencer, R.M.

[17] Buhusi, C.V., Meck, W.H.

[18] Pais, A.

[19] Protopapa, F., Hayashi, M.J., Kulashekhar, S., van der Zwaag, W., Battistella, G., Murray, M.M., Kanai, R., Bueti, D.

[20] Hayashi, M.J., Ditye, T., Harada, T., Hashiguchi, M., Sadato, N., Carlson, S., Walsh, V., Kanai, R.

[21] Karmarkar, U.R., Buonomano, D.V.

[22] Hayashi, M.J., van der Zwaag, W., Bueti, D., Kanai, R.

[23] Wald, R.M.

[24] Kuipers, T. (Ed.).

[25] Diederik, A.

[26] Vaccaro, J.A.

[27] Smolin, L. 
[28] Di Sia, P. A new unified theory based on the "primordial dynamic space" structure.

Preprint doi: 10.31219/osf.io/9rgce. https://osf.io/9rgce/.

[29] Di Sia, P. About Some Difficulties of Cosmology and New Ideas for Solving Them, Ergonomics International Journal (EOIJ), 4(2), 000231 (5 pp) (2020).

[30] Hameroff, S., Penrose, R.

[31] Santana Santos, F. (Ed.)

[32] Di Sia, P., Bhadra, N.K. Everything in a part: about the creation of universe and consciousness. Ergonomics International Journal (EOIJ), 4(1), 000228 (6 pp) (2020). 